\title{
Medium optimization for ethanol production with Clostridium autoethanogenum with carbon monoxide as sole carbon source
}

\author{
Ying Guo ${ }^{\mathrm{a}, \mathrm{b}}$, Jingliang $\mathrm{Xu}^{\mathrm{a}, *}$, Yu Zhang ${ }^{\mathrm{a}, \mathrm{b}}$, Huijuan $\mathrm{Xu}^{\mathrm{a}}$, Zhenhong Yuan ${ }^{\mathrm{a}, * *}$, Dong $\mathrm{Li}^{\mathrm{a}, \mathrm{b}}$ \\ a Key Laboratory of Renewable Energy and Gas Hydrate, Guangzhou Institute of Energy Conversion, Chinese Academy of Sciences, Guangzhou 510640, PR China \\ ${ }^{\mathrm{b}}$ Graduate University of Chinese Academy of Sciences, Beijing 100049, PR China
}

\section{A R T I C L E I N F O}

\section{Article history:}

Received 7 January 2010

Received in revised form 25 May 2010

Accepted 11 June 2010

Available online 8 July 2010

\section{Keywords:}

Syngas fermentation

Clostridium autoethanogenum

Response surface methodology

Artificial neural network

Genetic algorithm

\begin{abstract}
A B S T R A C T
Plackett-Burman and central composite designs were applied to optimize the medium for ethanol production by Clostridium autoethanogenum with $\mathrm{CO}$ as sole carbon source, and a medium containing $(\mathrm{g} / \mathrm{L}): \mathrm{NaCl} 1.0, \mathrm{KH}_{2} \mathrm{PO}_{4} 0.1, \mathrm{CaCl}_{2} 0.02$, yeast extract $0.15, \mathrm{MgSO}_{4} 0.116, \mathrm{NH}_{4} \mathrm{Cl} 1.694$ and $\mathrm{pH} 4.74$ was found optimal. The optimum ethanol yields predicted by response surface methodology (RSM) and an artificial neural network-genetic algorithm (ANN-GA) were 247.48 and $261.48 \mathrm{mg} / \mathrm{L}$, respectively. These values are similar to those obtained experimentally under the optimal conditions suggested by the statistical methods ( 254.26 and $259.64 \mathrm{mg} / \mathrm{L}$ ). The fitness of the ANN-GA model was higher than that of the RSM model. The yields obtained substantially exceed those previously reported $(60-70 \mathrm{mg} / \mathrm{L})$ with this organism.
\end{abstract}

(c) 2010 Elsevier Ltd. All rights reserved.

\section{Introduction}

Lignocellulosic biomass can be gasified into syngas and subsequently converted into ethanol by chemical or microbiological means (Huber et al., 2006). Some acetogens, such as Clostridium ljungdahlii, Clostridium autoethanogenum and Clostridium carboxidivorans, can convert $\mathrm{H}_{2}, \mathrm{CO}$ and $\mathrm{CO}_{2}$ to ethanol and acids (Abrini et al., 1994; Liou et al., 2005; Rajagopalan et al., 2002; Tanner et al., 1993). Microbial fermentation has high end-product specificity and does not require the application of high temperatures and pressures usually needed when chemical catalysts are employed (Ahmed and Lewis, 2007; Cotter et al., 2009a,b; Datar et al., 2004; Rajagopalan et al., 2002). A unique feature of $C$. autoethanogenum is its ability to grow on xylose. This characteristic may prove useful when hydrolysis and gasification are combined with fermentation. A majority of studies have concentrated on C. ljungdahlii or C. carboxidivorans, while few researchers have studied the fermentation capability of $C$. autoethanogenum. So, C. autoethanogenum was selected to be the candidate in our work.

The end products of autotrophs like C. autoethanogenum are highly depended on the $\mathrm{pH}$ of the medium. Lowering the $\mathrm{pH}$ increased ethanol production, while elevating the $\mathrm{pH}$ induced growth of the autotrophs (Datar et al., 2004; Gaddy and Clausen,

\footnotetext{
* Corresponding author. Tel.: +86 20 87057783; fax: +86 2087057737 .

** Corresponding author. Tel.: +86 20 87057735; fax: +86 2087057737.

E-mail addresses: xjl@ms.giec.ac.cn (J. Xu), yuanzh@ms.giec.ac.cn (Z. Yuan).
}

1992; Phillips et al., 1993). Phillips et al. (1993) designed a medium for culturing $C$. ljungdahlii, and a defined medium formulation was developed by Rajagopalan et al. (2002); however, it is not known if these media are ideal for ethanol production since ethanol is mostly generated under non-growth conditions (Klasson et al., 1992a,b).

Plackett-Burman (Plackett and Burman, 1946), artificial neural network (ANN)-genetic algorithm (GA) and central composite designs (CCD) (Box and Wilson, 1951; Hashimoto, 1997; Maier and Dandy, 2000; Mcculloch and Pitts, 1949; Morimoto et al., 1997a,b) have been proved to be useful for evaluating the relative significance of variables and optimization of the target metabolites production. ANN-GA used in CCD can address any required degree of accuracy and does not need to consider continuity or differentiability of the objective function (Nagata and Chu, 2003). It has been demonstrated that ANN-GA is more accurate than response surface methodology (RSM) (Duan et al., 2006; Erenturk and Erenturk, 2007; Garcia-Gimeno et al., 2005; Huang et al., 2007; Izadifar and Jahromi, 2007; Singh et al., 2009; Wang and Wan, 2009).

Therefore, in this study, Plackett-Burman, ANN-GA and CCD were used to screen the significant factors in the defined medium developed by Rajagopalan et al. (2002) for their influence on ethanol production. Plackett-Burman design was applied to screen the significant factors from the defined medium. Central composite design using RSM and ANN-GA was employed to access the optimum concentrations of the significant variables selected through Plackett-Burman design. 


\section{Methods}

\subsection{Microorganism and medium}

Clostridium autoethanogenum DSM 10061 was obtained from the Deutsche Sammlung von Mikroorganismen und Zellkulturen $\mathrm{GmbH}$ (Braunschweig, Germany) and revived in DSM medium 640 which contains $5 \mathrm{~g} / \mathrm{L}$ of xylose. C. autoethanogenum was transferred to the enrichment medium developed by Rajagopalan et al.(2002) and incubated until the culture reached an $\mathrm{OD}_{600}$ of $1.2(96-120 \mathrm{~h})$ without shaking, at $37^{\circ} \mathrm{C}$. Cells were harvested by centrifugation at $12,000 \mathrm{~g}$ for $10 \mathrm{~min}$, resuspended and inoculated into the fermentation medium (as per experiment design Tables 1 and $210 \%$ of inoculum, v/v) and cultured at $37^{\circ} \mathrm{C}$ with shaking at $150 \mathrm{rpm}$ for $60 \mathrm{~h}$ to ensure all of the $\mathrm{CO}$ had been exhausted and maximum ethanol production was obtained (Barik et al., 1988; Sim et al., 2008).

For medium optimization, the $\mathrm{pH}$ was fixed between $4.5(-1)$ and $5.0(+1), \mathrm{NH}_{4} \mathrm{Cl}$ and $\mathrm{KH}_{2} \mathrm{PO}_{4}$ concentrations were set at $1.0 \mathrm{~g}$ $(+1)$ and $0.1 \mathrm{~g}(+1)$ respectively, the $\mathrm{CaCl}_{2}$ concentration of 0.02 was set as the minimum $(-1)$, the amount of yeast extract was set between $0.15(-1)$ and $0.3(+1)$, and the $\mathrm{MgSO}_{4}$ and $\mathrm{NaCl}$ concentrations were set at $0.3 \mathrm{~g} / \mathrm{L}(+1), 0.15 \mathrm{~g} / \mathrm{L}(-1)$ and $1.0 \mathrm{~g} / \mathrm{L}(+1)$, $0.4 \mathrm{~g} / \mathrm{L}(-1)$ respectively (Table 1 ) (Andersch et al., 1984; McNeil and Kristiansen, 1987). Concentrations varied according to the statistic matrix (Tables 1 and 2). Enrichment medium with xylose instead of $\mathrm{CO}$ was used to initiate growth of $C$. autoethanogenum before fermentation in serum bottles capped with rubber stoppers. Fermentation with $\mathrm{CO}$ as carbon source was carried out with $20 \mathrm{ml}$ of medium in 100-ml infusion bags capped with rubber stoppers, $\mathrm{CO} / \mathrm{CO}_{2}(95 / 5, \mathrm{v} / \mathrm{v})$, at a gauge pressure of $1 \mathrm{~atm}$. The media were buffered with $10.0 \mathrm{~g} / \mathrm{L}$ of morpholinoethanesulfonic acid (MES). The composition for trace metals and vitamins was previously described (Rajagopalan et al., 2002). $2 \mathrm{~g} / \mathrm{L}$ of tryptase (Cotter et al., 2009a) was added to improve the ethanol production, $0.2 \mathrm{~g} / \mathrm{L}$ cysteine- $\mathrm{HCl}$ (Sim et al., 2008) was used as reducing agent, and $0.5 \mathrm{mg} / \mathrm{L}$ resazurin was added as redox indicator. The final $\mathrm{pH}$ of the medium was adjusted with $1 \mathrm{M} \mathrm{KOH}$ or $1 \mathrm{M} \mathrm{HCl}$. Before sterilization $\left(20 \mathrm{~min}, 121^{\circ} \mathrm{C}\right)$, the media were placed in an anaerobic chamber for 24-36 h. Vitamin solution and cysteine, sterilized by filtration, were added to the medium after autoclaving. All experiments were carried out in triplicate.

\subsection{Extraction of ethanol and analytical methods}

Cell free culture supernatant was obtained by centrifugation at $12,000 \mathrm{~g}$ for $10 \mathrm{~min}$ at $4{ }^{\circ} \mathrm{C}$ and then frozen at $4{ }^{\circ} \mathrm{C}$ until analysis.
Ethanol concentration was measured with a gas chromatograph (Agilent 6820) equipped with a flame ionization detector (FID) and a fused-silica capillary column (DB-FFAP, $30 \mathrm{~m} \times 0.25 \mathrm{~mm} \times$ $0.25 \mu \mathrm{m}$ ). Nitrogen was used as carrier gas at a flow rate of $30 \mathrm{~mL} / \mathrm{min}$ and split ratio of $1 / 50$.The injector and detector temperature were 250 and $300^{\circ} \mathrm{C}$, respectively. The initial oven temperature was $40^{\circ} \mathrm{C}$. After $5 \mathrm{~min}$, the temperature was increased at a rate of $20^{\circ} \mathrm{C} / \mathrm{min}$ until it reached $140{ }^{\circ} \mathrm{C}$, and then increased at a rate of $40^{\circ} \mathrm{C} / \mathrm{min}$ until it reached $250^{\circ} \mathrm{C}$.

\subsection{Plackett-Burman design}

The Plackett-Burman design was firstly employed to identify the significant variables on ethanol production from the main inorganic components, yeast extract and $\mathrm{pH}$. According to Plackett-Burman design (Plackett and Burman, 1946), each variable is represented at two levels, high $(+1)$ and low $(-1)$. In this study, seven assigned variables together with four dummy variables were tested in 12 experiments. The effect of variables was firstly computed as followed:

$E_{V i}=\frac{\sum y_{V i(+)}-\sum y_{V i(-)}}{N / 2}$

where $E_{V i}$ represents the effect of variable $i, y_{V i(+)}$ and $y_{V i(-)}$ are the response of the high and low levels of variable $i$, respectively, $N$ stands for number of trials.

And then the standard deviation $(S D)$ of dummies was calculated by Eq. (2):

$S D=\sqrt{\frac{\sum\left(E_{d}\right)^{2}}{n}}$

where $S D$ represents the effect of dummy variables, and $n$ is the number of the dummy variables. $T$-test was finally performed as follows to determine the significance of these factors.

$t_{V i}=\frac{E_{V i}}{S D}$

Four dummy variables were studied in 12 experiments to calculate the standard error. $R^{2}$ (the coefficient of determination) was used to examine the fitness of the Plackett-Burman design. Average value of ethanol production was taken as the response. Variables with confidence levels above $90 \%$ were considered to have significant effect on ethanol production and thus were used for further optimization.

Table 1

The Plackett-Burman design for screening variables in ethanol production by using Clostridium autoethanogenum.

\begin{tabular}{|c|c|c|c|c|c|c|c|c|c|}
\hline \multirow[t]{3}{*}{ Trail } & Levels & \multicolumn{7}{|l|}{ Factors } & \multirow[t]{3}{*}{ Ethanol $(\mathrm{mg} / \mathrm{L})$} \\
\hline & 1 & 1.000 & 1.000 & 0.100 & 0.300 & 0.040 & 0.300 & 5.00 & \\
\hline & -1 & 0.400 & 0.600 & 0.040 & 0.150 & 0.020 & 0.150 & 4.50 & \\
\hline 1 & & -1 & -1 & -1 & 1 & 1 & 1 & -1 & $38.1 \pm 1.52$ \\
\hline 2 & & -1 & 1 & -1 & -1 & -1 & 1 & 1 & $97.8 \pm 4.31$ \\
\hline 3 & & -1 & -1 & 1 & 1 & 1 & -1 & 1 & $43.4 \pm 1.35$ \\
\hline 4 & & 1 & -1 & 1 & 1 & -1 & 1 & -1 & $69.6 \pm 3.12$ \\
\hline 5 & & 1 & -1 & 1 & -1 & -1 & -1 & 1 & $96.0 \pm 4.24$ \\
\hline 6 & & 1 & 1 & 1 & -1 & 1 & 1 & -1 & $164.94 \pm 5.67$ \\
\hline 7 & & 1 & 1 & -1 & 1 & -1 & -1 & -1 & $143.10 \pm 5.12$ \\
\hline 8 & & -1 & 1 & 1 & -1 & 1 & -1 & -1 & $144.81 \pm 5.01$ \\
\hline 9 & & 1 & -1 & -1 & -1 & 1 & 1 & 1 & $79.84 \pm 4.31$ \\
\hline 10 & & -1 & -1 & -1 & -1 & -1 & -1 & -1 & $116.45 \pm 3.62$ \\
\hline 11 & & -1 & 1 & 1 & 1 & -1 & 1 & 1 & $36.62 \pm 1.67$ \\
\hline 12 & & 1 & 1 & -1 & 1 & 1 & -1 & 1 & $45.27 \pm 2.14$ \\
\hline
\end{tabular}


Table 2

The experimental results together with RSM and ANN predictions of CCD design in the terms of ethanol yield.

\begin{tabular}{|c|c|c|c|c|c|c|c|}
\hline \multirow[t]{7}{*}{ Trail } & \multirow{7}{*}{$\begin{array}{l}\text { Levels } \\
\begin{array}{l} \\
1.68179 \\
1.00000 \\
0 \\
-1.00000 \\
-1.68179\end{array}\end{array}$} & \multicolumn{3}{|l|}{ Factors } & \multicolumn{3}{|c|}{ Ethanol $(\mathrm{mg} / \mathrm{L})$} \\
\hline & & \multirow{6}{*}{$\begin{array}{c}\mathrm{NH}_{4} \mathrm{Cl} \\
X_{1}(\mathrm{~g} / \mathrm{L}) \\
2.3409 \\
2.0000 \\
1.5000 \\
1.0000 \\
0.6591\end{array}$} & \multirow{6}{*}{$\begin{array}{c}\mathrm{MgSO}_{4} \\
X_{2}(\mathrm{~g} / \mathrm{L}) \\
0.1841 \\
0.1500 \\
0.1000 \\
0.0500 \\
0.0159\end{array}$} & \multirow{6}{*}{$\begin{array}{l}\mathrm{pH} \\
X_{3} \\
5.00 \\
4.80 \\
4.50 \\
4.20 \\
4.00\end{array}$} & & & \\
\hline & & & & & RSM & ANN & Experimental \\
\hline & & & & & & & \\
\hline & & & & & & & \\
\hline & & & & & & & \\
\hline & & & & & & & \\
\hline 1 & & -1.00000 & -1.00000 & -1.00000 & 158.26 & 150.42 & $152.68 \pm 4.12$ \\
\hline 2 & & 1.00000 & -1.00000 & -1.00000 & 150.41 & 144.22 & $145.85 \pm 5.07$ \\
\hline 3 & & -1.00000 & 1.00000 & -1.00000 & 173.27 & 168.86 & $168.00 \pm 4.19$ \\
\hline 4 & & 1.00000 & 1.00000 & -1.00000 & 234.88 & 241.08 & $242.62 \pm 5.52$ \\
\hline 5 & & -1.00000 & -1.00000 & 1.00000 & 210.04 & 200.15 & $202.29 \pm 5.15$ \\
\hline 6 & & 1.00000 & -1.00000 & 1.00000 & 180.23 & 180.83 & $185.49 \pm 4.01$ \\
\hline 7 & & -1.00000 & 1.00000 & 1.00000 & 199.85 & 205.45 & $204.40 \pm 5.21$ \\
\hline 8 & & 1.00000 & 1.00000 & 1.00000 & 239.49 & 237.29 & $245.07 \pm 5.54$ \\
\hline 9 & & -1.68179 & 0.00000 & 0.00000 & 181.02 & 190.53 & $189.37 \pm 4.75$ \\
\hline 10 & & 1.68179 & 0.00000 & 0.00000 & 207.75 & 205.36 & $199.41 \pm 3.35$ \\
\hline 11 & & 0.00000 & -1.68179 & 0.00000 & 140.06 & 151.58 & $147.57 \pm 4.96$ \\
\hline 12 & & 0.00000 & 1.68179 & 0.00000 & 202.51 & 197.24 & $195.01 \pm 5.65$ \\
\hline 13 & & 0.00000 & 0.00000 & -1.68179 & 197.78 & 203.86 & $202.34 \pm 4.87$ \\
\hline 14 & & 0.00000 & 0.00000 & 1.68179 & 245.20 & 246.42 & $240.65 \pm 5.09$ \\
\hline 15 & & 0.00000 & 0.00000 & 0.00000 & 235.57 & 233.54 & $235.91 \pm 3.72$ \\
\hline 16 & & 0.00000 & 0.00000 & 0.00000 & 235.57 & 233.54 & $235.83 \pm 3.65$ \\
\hline 17 & & 0.00000 & 0.00000 & 0.00000 & 235.57 & 233.54 & $235.62 \pm 3.85$ \\
\hline 18 & & 0.00000 & 0.00000 & 0.00000 & 235.57 & 233.54 & $235.46 \pm 4.21$ \\
\hline 19 & & 0.00000 & 0.00000 & 0.00000 & 235.57 & 233.54 & $235.31 \pm 3.97$ \\
\hline 20 & & 0.00000 & 0.00000 & 0.00000 & 235.57 & 233.54 & $235.29 \pm 4.43$ \\
\hline
\end{tabular}

\subsection{Central composite design}

A five-variable central composite design was used to optimize important valuables selected by the Plackett-Burman design. Central composite design (Box and Wilson, 1951) consists of a $2^{k}$ full factorial design, $2 k$ axial designs at a distance $\alpha$ from the origin, and $m$ center points, where $k$ is the number of valuables and $m$ is more than 1 . Eq. (4):

$X_{i}=\frac{\left(A_{i}-A_{0}\right)}{\Delta A}$

describes the relationship between the coded values and actual values, where $X_{i}$ represents coded value, $A_{i}$ is the actual value, $A_{0}$ is the actual value of the variables at the centre point, and $\Delta A$ is the step change.

\subsubsection{Response surface methodology}

The statistical technique, Response Surface Methodology, was employed to optimize the screened variables, and the relationship between variables and responses was expressed by a second order polynomial Eq. (5):

$Y=\beta_{0}+\sum_{i=1}^{3} \beta_{i} X_{i}+\sum_{i=1}^{3} \beta_{i i} X_{i}^{2}+\sum_{i=1}^{2} \sum_{j=i+1}^{3} \beta_{i} \beta_{j} X_{i} X_{j}$

where $Y$ is the predictive response; $\beta_{0}$ is offset term; $X_{i}$, and $X_{j}$ stand for the independent variables; $\beta_{i}, \beta_{i i}$ and $\beta_{i j}$ represent regression coefficients of the model.

\subsubsection{Artificial neural network and genetic algorithm}

ANN model together with GA was also employed to access the optimum concentration. The variables selected through PlackettBurman design were included as input variables, and the yield of ethanol as output, and they were scaled by Eq. (6):

$X^{*}=2 \frac{X-X_{\min }}{X_{\max }-X_{\min }}-1$

$Y^{*}=\frac{Y-0}{500-0}$
And these values were rescaled by Eq. (7):

$$
\begin{gathered}
X=\frac{\left(X_{\max }-X_{\min }\right)\left(X^{*}+1\right)}{2}+X_{\min } \\
Y=500 \times Y^{*}
\end{gathered}
$$

\subsection{Statistical analysis}

Experimental designs and corresponding data were conducted with the help of Minitab 15.0 (Minitab Inc., Pennsylvania, USA).The ANN models and GA described in this study were implemented with Matlab v6.5 software.

Table 3

Effects of Plackett-Burman design for ethanol production.

\begin{tabular}{llrrl}
\hline & Symbol & \multicolumn{1}{c}{ Effect } & $t$-value & $P$-value \\
\hline $\mathrm{NaCl}(\mathrm{g} / \mathrm{L})$ & $x_{1}$ & 20.26 & 1.59 & 0.187 \\
$\mathrm{NH}_{4} \mathrm{Cl}(\mathrm{g} / \mathrm{L})$ & $x_{2}$ & 31.50 & 2.47 & 0.069 \\
$\mathrm{KH}_{2} \mathrm{PO}_{4}(\mathrm{~g} / \mathrm{L})$ & $x_{3}$ & 5.81 & 0.46 & 0.672 \\
$\mathrm{MgSO}_{4}(\mathrm{~g} / \mathrm{L})$ & $x_{4}$ & -53.94 & -4.23 & 0.013 \\
$\mathrm{CaCl}_{2}(\mathrm{~g} / \mathrm{L})$ & $x_{5}$ & -7.20 & -0.56 & 0.602 \\
$\mathrm{Yeast}$ extract $(\mathrm{g} / \mathrm{L})$ & $x_{6}$ & -17.00 & -1.33 & 0.253 \\
$\mathrm{pH}$ & $x_{7}$ & -46.36 & -3.64 & 0.022 \\
\hline
\end{tabular}

$S D=22.09, R^{2}=91.31 \%, R^{2}(\operatorname{adj})=76.11 \%$.

Table 4

Analysis of variance for the quadratic response surface model.

\begin{tabular}{lclrc}
\hline Term & Coefficient & Standard error & $t$-value & $P$-value \\
\hline Constant & 235.573 & 3.087 & 76.320 & $<0.0001$ \\
$X_{1}$ & 7.948 & 2.048 & 3.881 & 0.003 \\
$X_{2}$ & 18.567 & 2.048 & 9.066 & $<0.0001$ \\
$X_{3}$ & 14.097 & 2.048 & 6.884 & 0.001 \\
$X_{1}^{2}$ & -14.563 & 1.994 & -7.305 & $<0.0001$ \\
$X_{2}^{2}$ & -22.728 & 1.994 & -11.401 & $<0.0001$ \\
$X_{3}^{2}$ & -4.978 & 1.994 & -2.497 & 0.032 \\
$X_{1} X_{2}$ & 17.364 & 2.676 & 6.489 & $<0.0001$ \\
$X_{1} X_{3}$ & -5.491 & 2.676 & -2.052 & 0.067 \\
$X_{2} X_{3}$ & -6.302 & 2.676 & -2.355 & 0.040 \\
\hline
\end{tabular}



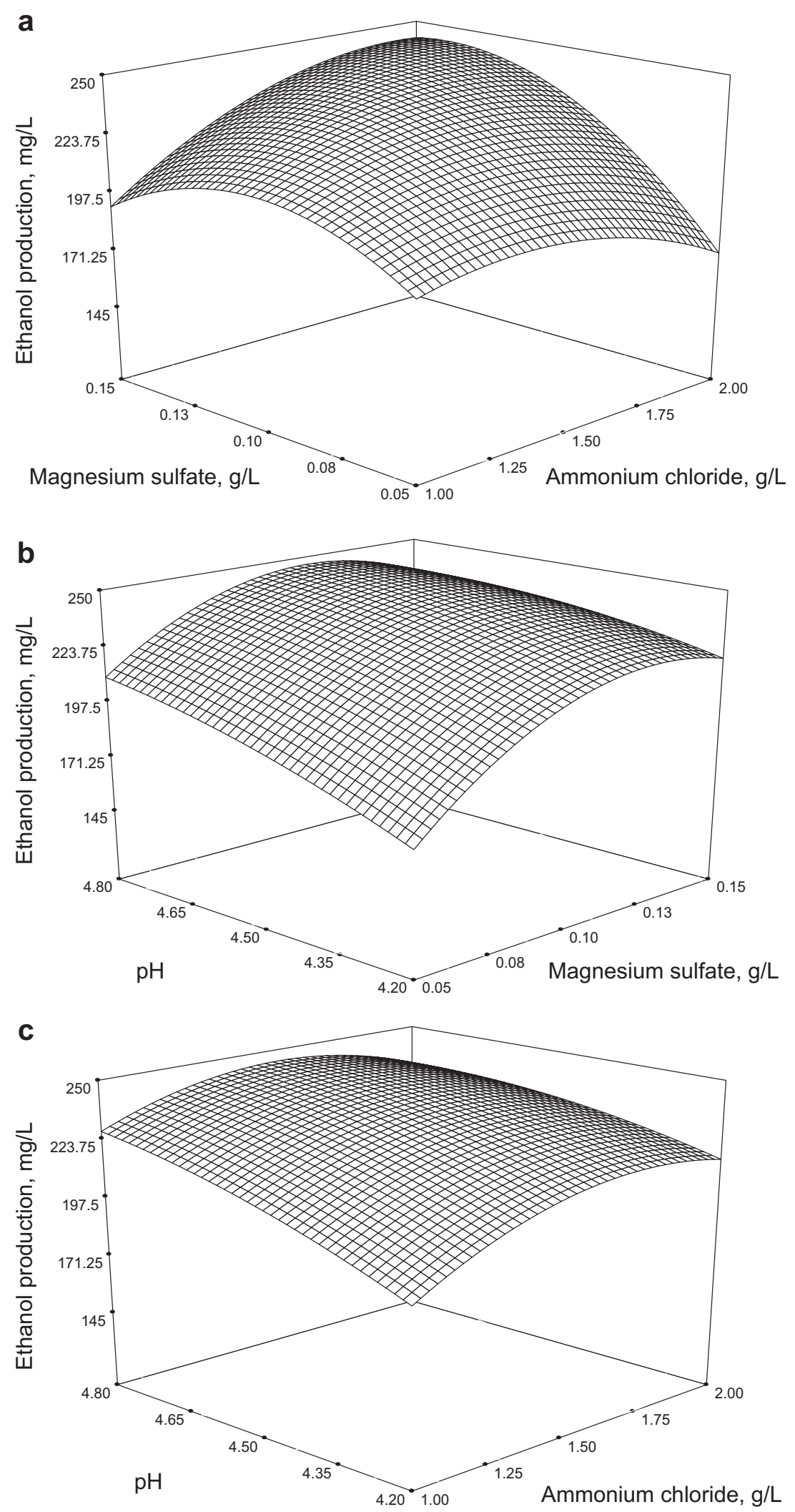

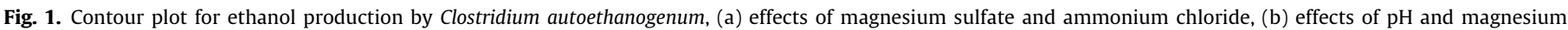
sulfate, (c) effects of $\mathrm{pH}$ and ammonium chloride. 


\section{Results and discussion}

\subsection{Plackett-Burman design}

Plackett-Burman design was adopted to screen the important fermentation parameters which have significant effects on ethanol production with $C$. autoethanogenum. $\mathrm{NaCl}, \mathrm{NH}_{4} \mathrm{Cl}, \mathrm{KH}_{2} \mathrm{PO}_{4}, \mathrm{MgSO}_{4}$, $\mathrm{CaCl}_{2}$, yeast extract and pH were selected through 12 runs with the Plackett-Burman design. The design matrix and its corresponding yield are illustrated in Table 1 . Table 3 shows the main effects of each medium constituent, its associated $t$-values and $p$-values. According to the Plackett-Burman design, $\mathrm{NaCl}, \mathrm{NH}_{4} \mathrm{Cl}$, and $\mathrm{KH}_{2} \mathrm{PO}_{4}$ had positive effects and thus a +1 level would be expected to improve the production of ethanol. $\mathrm{MgSO}_{4}, \mathrm{CaCl}_{2}$, Yeast extract, and $\mathrm{pH}$ showed negative effects, and a -1 level would be helpful for the high production of ethanol. As a result, a medium containing $(\mathrm{g} / \mathrm{L}), \mathrm{NaCl} 1, \mathrm{KH}_{2} \mathrm{PO}_{4} 0.1, \mathrm{CaCl}_{2} 0.02$, yeast extract 0.15 was chosen. Dummy variables were used to calculate standard deviation (SD), $t$-values and $p$-values. The $S D$ of 22.09 indicated interactions among the factors. $\mathrm{MgSO}_{4}, \mathrm{NH}_{4} \mathrm{Cl}$ and $\mathrm{pH}$, which had a $p$ value less than 0.1 , were significant compositions that affected the yield of ethanol production. In the results listed in Table $3, R^{2}$ was 0.9131 , which means that model could explain $91.31 \%$ of the total variations in the system. The optimum value of $\mathrm{MgSO}_{4}, \mathrm{NH}_{4} \mathrm{Cl}$ and $\mathrm{pH}$, were further investigated by $\mathrm{CCD}$.

\subsection{Central composite design}

$\mathrm{MgSO}_{4}, \mathrm{NH}_{4} \mathrm{Cl}$ and $\mathrm{pH}$ screened by the Plackett-Burman design were further studied by central composite design to establish their optimum levels. The central composite design consisted of a $2^{3}$ full factorial design, $2 * 3$ axial designs and 6 center points, that is, a total number of 20 experiments. The design matrix of CCD, the variables and corresponding results are presented in Table 2.

\subsubsection{Response surface methodology}

The relationship among $\mathrm{MgSO}_{4}, \mathrm{NH}_{4} \mathrm{Cl}$ and $\mathrm{pH}$ were identified by RSM. Table 4 presents an analysis of variance (ANOVA) for the quadratic response surface model. According to the regression analysis of the experimental design, the interactive model term $\mathrm{NH}_{4} \mathrm{Cl} * \mathrm{pH}$, with a $p$-value of more than 0.05 , was insignificant, while all the other model terms $(p<0.05)$ were significant. The fitness of the polynomial model equation was judged by $R^{2}$. A $R^{2}$ value of $97.34 \%$ and an adjusted $R^{2}$ value of $94.94 \%$ confirmed good agreement. Therefore, the results in terms of the production of ethanol can be illustrated by the following quadratic regression equations:

$$
\begin{aligned}
Y= & 235.573+7.984 X_{1}+18.567 X_{2}+14.097 X_{3}-14.563 X_{1}^{2} \\
& -22.784 X_{2}^{2}-4.978 X_{3}^{2}+17.364 X_{1} X_{2}-6.302 X_{2} X_{3}
\end{aligned}
$$

where the production of ethanol as $Y$ is a multiple function of the $\mathrm{MgSO}_{4}$ and $\mathrm{NH}_{4} \mathrm{Cl}$ concentrations and $\mathrm{pH}$.

The RSM predicted model is presented as three-dimensional graphs in Fig. 1a-c to indicate the interaction among the variables that influenced the production of ethanol. The optimal process parameters of RSM model were established by the central point of the contour plot. The predicted highest ethanol production of $247.48 \mathrm{mg} / \mathrm{L}$ could be obtained at a concentration $0.120 \mathrm{~g} / \mathrm{L} \mathrm{MgSO}_{4}$ and $1.661 \mathrm{~g} / \mathrm{L} \mathrm{NH}_{4} \mathrm{Cl}$ at a $\mathrm{pH} 4.80$. Experimental ethanol production of $254.26 \mathrm{mg} / \mathrm{L}$ was obtained under these optimum conditions.

\subsubsection{Artificial neural network and genetic algorithm}

Fig. 2 compares the ethanol yields predicted by the ANN and RSM with the corresponding experimental yields. The standard deviation $S$ was introduced to analyze residual of ANN and RSM.

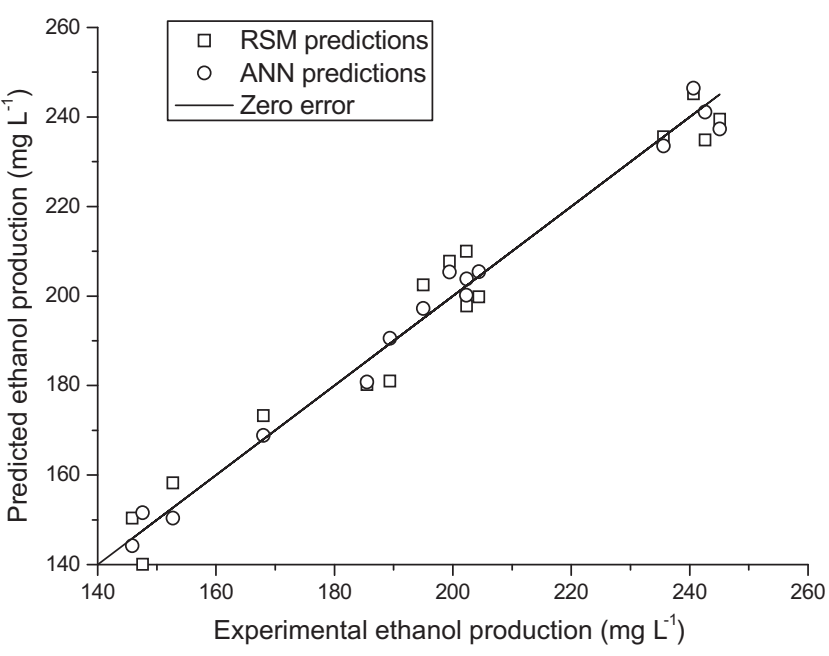

Fig. 2. RSM and ANN predictions versus experimental values.

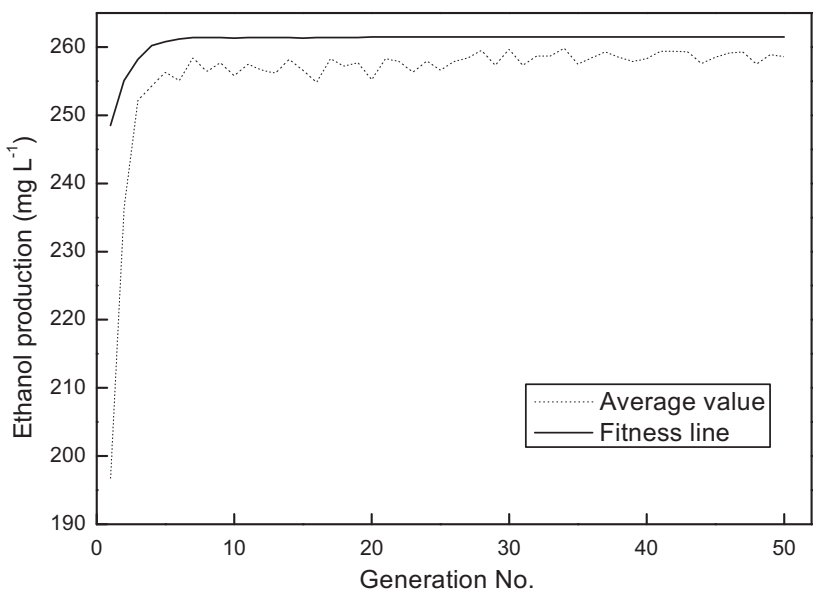

Fig. 3. Evolution of the fitness and average value (ethanol production) over the 50 generations in the genetic algorithm.

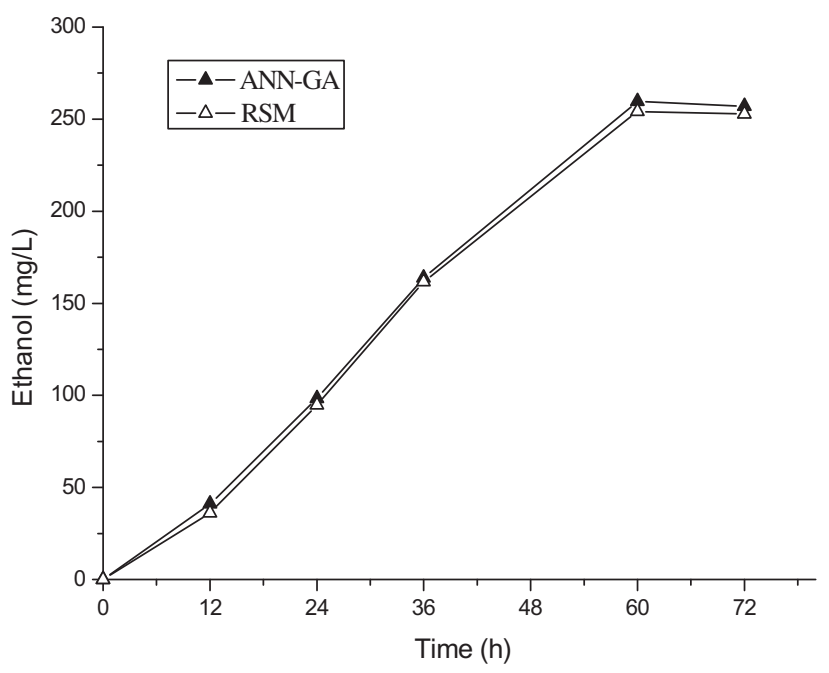

Fig. 4. Ethanol production using the optimal medium (describe medium) suggested by response surface methodology and artificial neural network-genetic algorithm. 
$S_{\text {RSM } / \text { ANN }}=\sqrt{\frac{\sum\left(\text { Prediction }_{\text {RSM } / \text { ANN }}-{\text { Zero error })^{2}}^{2}\right.}{20}}$

Since the $S_{\text {RSM }}$ of 5.35 was higher than the $S_{\text {ANN }}$ of 3.29 , the fitness and prediction accuracy of the ANN model was higher than that of the RSM. For the GA-derived optimal conditions, optimum values of ethanol production were obtained over 50 generations (Fig. 3). At $\mathrm{pH} 4.74$ and $\mathrm{MgSO}_{4}$ and $\mathrm{NH}_{4} \mathrm{Cl}$ concentrations of 0.116 and $1.694 \mathrm{~g} / \mathrm{L}$, respectively, the maximum achievable ethanol production was $261.48 \mathrm{mg} / \mathrm{L}$ according to the ANN-GA model. The experimental ethanol yield under the above conditions was $259.64 \mathrm{mg} / \mathrm{L}$, which was near $254.26 \mathrm{mg} / \mathrm{L}$, the ethanol yield obtained under the condition recommended by RSM model. Therefore, the ANN-GA model performed better than RSM model in the optimization studies. Fig. 4 shows ethanol production over time using the optimal media suggested by RSM and ANN-GA. The maximum ethanol production was obtained at $60 \mathrm{~h}$. After $60 \mathrm{~h}$, production decreased slightly, which is attributable to the depletion of CO.

It is noteworthy that the end-products of autotrophs also depend on the mass transfer of substrate to the cell and the redox potential environment (Phillips et al., 1993; Sim et al., 2008). In the infusion bag system, the effects of $\mathrm{CO}$ and reducing environment were negligible. The pressure in the infusion bag was stable at $1.0 \mathrm{~atm}$ and thus the different amounts of $\mathrm{CO}$, in the bag, had the same chance to dissolve. Reducing environments were the same for all samples at the beginning $(0.2 \mathrm{~g} / \mathrm{L}$ cysteine- $\mathrm{HCl})$. In this study, the effect of key CO-utilizing enzymes during fermentation was attributed to the different composition of the media which also play a significant role in the redox environment. The $\mathrm{pH}$ was adjusted with $\mathrm{KOH}$ or $\mathrm{HCl}$, and different $\mathrm{pHs}$ resulted in different concentrations of $\mathrm{Cl}^{-}$and $\mathrm{K}^{+}$. However, this concentration was relatively low compared with the existing $\mathrm{Cl}^{-}$(existing as $\mathrm{KCl}, \mathrm{NaCl}$, $\mathrm{CaCl}_{2}$ and $\mathrm{NH}_{4} \mathrm{Cl}$ ) and $\mathrm{K}^{+}$(existing as $\mathrm{KCl}$ and $\mathrm{KH}_{2} \mathrm{PO}_{4}$ ). Our optimal ethanol concentration, around $260 \mathrm{mg} / \mathrm{L}$ was still low compared with ethanol yields obtained with enzymes or chemical catalysis which can be as high as $50 \mathrm{~g} / \mathrm{L}$ in less than three days (Munasinghe and Khanal, 2010). Therefore further studies are required to improve the yield of ethanol with this bacterium cultured on syngas.

\section{Conclusion}

Plackett-Burman and central composite designs were used to optimize ethanol production from $\mathrm{CO}$ by $C$. autoethanogenum. The predicted and experimentally achieved yields were in good agreement, but the yield has to be improved further for this bacterium to be useful for large-scale ethanol production from syngas.

\section{Acknowledgements}

This work was funded by the National High Technology Research and Development Program of China (863 program, No. 2007AA05Z406) and the Knowledge Innovation Program of the Chinese Academy of Sciences (No. KGCX2-YW-335, KSCX-YW-11A3 and KSCX2-YW-G-075-09).

\section{References}

Abrini, J., Naveau, H., Nyns, E.J., 1994. Clostridium autoethanogenum, sp-nov, an anaerobic bacterium that produces ethanol from carbon-monoxide. Arch. Microbiol. 161, 345-351.

Ahmed, A., Lewis, R.S., 2007. Fermentation of biomass-generated synthesis gas: effects of nitric oxide. Biotechnol. Bioeng. 97, 1080-1086.
Andersch, W., Bahl, H., Oulevey, J., Gottschalk, G., 1984. Comparison of acidproducing and solvent-producing cells of Clostridium acetobutylicum. Syst. Appl. Microbiol. 5, 272.

Barik, S., Prieto, S., Harrison, S.B., Clausen, E.C., Gaddy, J.L., 1988. Biological production of alcohols from coal through indirect liquefaction. Appl. Biochem. Biotechnol. 18, 363-378.

Box, G.E.P., Wilson, K.B., 1951. On the experimental attainment of optimum conditions. J. Roy. Stat. Soc. B Stat. Meth. 13, 1-45.

Cotter, J.L., Chinn, M.S., Grunden, A.M., 2009a. Ethanol and acetate production by Clostridium ljungdahlii and Clostridium autoethanogenum using resting cells. Bioprocess Biosyst. Eng. 32, 369-380.

Cotter, J.L., Chinn, M.S., Grunden, A.M., 2009b. Influence of process parameters on growth of Clostridium ljungdahlii and Clostridium autoethanogenum on synthesis gas. Enzyme Microb. Technol. 44, 281-288.

Datar, R.P., Shenkman, R.M., Cateni, B.G., Huhnke, R.L., Lewis, R.S., 2004. Fermentation of biomass-generated producer gas to ethanol. Biotechnol. Bioeng. 86, 587-594.

Duan, S.B., Shi, Z.P., Feng, H.J., Duan, Z.Y., Mao, Z.G., 2006. An on-line adaptive control based on $\mathrm{DO} / \mathrm{pH}$ measurements and ANN pattern recognition model for fed-batch cultivation. Biochem. Eng. J. 30, 88-96.

Erenturk, S., Erenturk, K., 2007. Comparison of genetic algorithm and neural network approaches for the drying process of carrot. J. Food Eng. 78, 905-912.

Gaddy, J.L., Clausen, E.C., 1992. Clostridium ljungdahlii, an aerobic ethanol and acetate producing microorganism U.S. patent 5,173,429.

Garcia-Gimeno, R.M., Hervas-Martinez, C., Rodriguez-Perez, R., Zurera-Cosano, G., 2005. Modelling the growth of Leuconostoc mesenteroides by artificial neural networks. Int. J. Food Microbiol. 105, 317-332.

Hashimoto, Y., 1997. Applications of artificial neural networks and genetic algorithms to agricultural systems. Comput. Electron. Agric. 18, 71-72.

Huang, J., Mei, L.H., Xia, J., 2007. Application of artificial neural network coupling particle swarm optimization algorithm to biocatalytic production of GABA. Biotechnol. Bioeng. 96, 924-931.

Huber, G.W., Iborra, S., Corma, A., 2006. Synthesis of transportation fuels from biomass: chemistry, catalysts, and engineering. Chem. Rev. 106, 4044-4098.

Izadifar, M., Jahromi, M.Z., 2007. Application of genetic algorithm for optimization of vegetable oil hydrogenation process. J. Food Eng. 78, 1-8.

Klasson, K.T., Ackerson, C.M.D., Clausen, E.C., Gaddy, J.L., 1992a. Biological conversion of synthesis gas to fuels. Int. J. Hydrogen Energy 7, 281-288.

Klasson, K.T., Ackerson, M.D., Clausen, E.C., 1992b. Bioconversion of synthesis gas into liquid or gaseous fuels. Enzyme Microb. Technol. 14, 602-608.

Liou, J.S.C., Balkwill, D.L., Drake, G.R., Tanner, R.S., 2005. Clostridium carboxidivorans sp-nov., a solvent-producing clostridium isolated from an agricultural settling lagoon, and reclassification of the acetogen Clostridium scatologenes strain SL1 as Clostridium drakei sp-nov.. Int. J. Syst. Evol. Microbiol. 55, 2085-2091.

Maier, H.R., Dandy, G.C., 2000. Neural networks for the prediction and forecasting of water resources variables: a review of modelling issues and applications. Environ. Modell. Softw. 15, 101-124.

Mcculloch, W.S., Pitts, W., 1949. How nervous structures have ideas. T. Am. Neurol. Assoc., 10-16.

McNeil, B., Kristiansen, B., 1987. The effect of medium composition on the acetone butanol fermentation in continuous culture. Biotechnol. Bioeng. 29, 383-387.

Morimoto, T., DeBaerdemaeker, J., Hashimoto, Y., 1997a. An intelligent approach for optimal control of fruit-storage process using neural networks and genetic algorithms. Comput. Electron. Agric. 18, 205-224.

Morimoto, T., Purwanto, W., Suzuki, J., Hashimoto, Y., 1997b. Optimization of heat treatment for fruit during storage using neural networks and genetic algorithms. Comput. Electron. Agric. 19, 87-101.

Munasinghe, P.C., Khanal, S.K., 2010. Biomass-derived syngas fermentation into biofuels: opportunities and challenges. Bioresour. Technol. 101, 5013-5022.

Nagata, Y., Chu, K.H., 2003. Optimization of a fermentation medium using neural networks and genetic algorithms. Biotechnol. Lett. 25, 1837-1842.

Phillips, J.R., Klasson, K.T., Clausen, E.C., Gaddy, J.L., 1993. Biological production of ethanol from coal synthesis gas-medium development studies. Appl. Biochem. Biotechnol. 39, 559-571.

Plackett, R.L., Burman, J.P., 1946. The design of optimum multifactorial experiments. Biometrika 33, 305-325.

Rajagopalan, S., Datar, R.P., Lewis, R.S., 2002. Formation of ethanol from carbon monoxide via a new microbial catalyst. Biomass Bioenergy 23, 487-493.

Sim, J.H., Kamaruddin, A.H., Long, W.S., 2008. Biocatalytic conversion of CO to acetic acid by Clostridium aceticum-Medium optimization using response surface methodology (RSM). Biochem. Eng. J. 40, 337-347.

Singh, V., Khan, M., Khan, S., Tripathi, C.K.M., 2009. Optimization of actinomycin V production by Streptomyces triostinicus using artificial neural network and genetic algorithm. Appl. Microbiol. Biotechnol. 82, 379-385.

Tanner, R.S., Miller, L.M., Yang, D., 1993. Clostridium-ljungdahlii sp-nov, an acetogenic species in clostridial ribosomal-RNA homology group-I. Int. J. Syst. Bacteriol. 43, 232-236.

Wang, J.L., Wan, W., 2009. Optimization of fermentative hydrogen production process using genetic algorithm based on neural network and response surface methodology. Int. J. Hydrogen Energy 34, 255-261. 